\title{
Enhancement of the Wear and Corrosion Resistance of DLC/ oxynitriding Duplex-treated PM30 Steel by the Asymmetric Bipolar-pulsed Plasma Enhanced CVD
}

\author{
Shih-Hsien CHANG, ${ }^{1) *}$ Chang-Kai PENG, ${ }^{1)}$ Kuo-Tsung HUANG ${ }^{2)}$ and Chung-Ming LIU ${ }^{3,4)}$ \\ 1) Department of Materials and Mineral Resources Engineering, National Taipei University of Technology, Taipei, 10608 \\ Taiwan, ROC. $\quad$ 2) Department of Auto-Mechanics, National Kangshan Agricultural Industrial Senior High School, \\ Kaohsiung, 82049 Taiwan, ROC. $\quad 3$ 3) School of Dentistry, China Medical University, Taichung City, 40402 Taiwan, ROC. \\ 4) Biomedical Technology R\&D Center, China Medical University Hospital, Taichung City, 40402 Taiwan, ROC.
}

(Received on February 26, 2018; accepted on April 25, 2018)

\begin{abstract}
In the present research, DLC films are produced by asymmetric bipolar pulsed plasma enhanced CVD after preparing oxynitride-treated PM30 steel. The experimental parameters include various $\mathrm{CH}_{4}$ gas flows $(3,7,11,15$ and $19 \mathrm{sccm})$ with asymmetric bipolar pulsed voltages $(-15+10 \%)$ and a deposition time of $90 \mathrm{~min}$, respectively. In order to evaluate the properties of the DLC films for oxynitride-treated PM30 steel, Raman spectroscopy analysis, adhesion tests, nano-indentation, wear tests, and corrosion resistance inspections were performed. The experimental results reveal that the DLC/oxynitride duplex coating layers have better properties when the DLC films are treated with an appropriate $\mathrm{CH}_{4}$ gas flow (15 sccm). Meanwhile, the coatings possess the highest hardness and elastic modulus (5.91 and $89.87 \mathrm{GPa}$, respectively), the lowest wear loss volume (for axial loads of 2 and $5 \mathrm{~N}$ of $3.82 \times 10^{-3}$ and $5.49 \times 10^{-3} \mathrm{~mm}^{3}$, respectively), the lowest corrosion current $\left(1.43 \times 10^{-4} \mathrm{~A} \cdot \mathrm{cm}^{-2}\right)$, and the highest polarization resistance $(5.32 \times$ $10^{2} \Omega \cdot \mathrm{cm}^{2}$ ) after a 3.5 mass \% NaCl corrosion test. This study also confirms that the wear and corrosion resistance of DLC/oxynitride duplex-treated PM30 steel can be effectively improved via asymmetric bipolar pulsed plasma enhanced CVD.
\end{abstract}

KEY WORDS: DLC; asymmetric bipolar-pulsed plasma enhanced CVD; oxynitriding; PM30 steel; wear; corrosion resistance.

\section{Introduction}

High speed steels (HSS) are more specifically used as cutting tools and wear parts. Generally, a combination of high strength, wear resistance and hardness together with an appreciable toughness compared with other materials used as tools and fatigue resistance is required. ${ }^{1)}$ The PM30 family of high speed steels was developed in Sweden in the 1960 's and is now widely used. ${ }^{2)}$ Among them, PM30 steel is a cobalt alloyed high performance PM high speed steel. The cobalt addition of approximate $8.5 \%$ has a positive influence on the hot strength/hardness, temper resistance and modulus of elasticity. ${ }^{3)}$ Therefore, various coating techniques improve the life and productivity of PM30 steels are widely used in the industry. ${ }^{4-6)}$

Nitriding is a thermo-chemical process with nitrogen diffusion, which leads to increase the surface hardness of the treated steels. It reveals an effective improvement of thermal fatigue characteristics due to the effects of compressive stress and the hardened surface. ${ }^{7}$ The previous studies also indicated that oxygen addition can increase the efficiency

\footnotetext{
* Corresponding author: E-mail: changsh@ntut.edu.tw DOI: http://dx.doi.org/10.2355/isijinternational.ISIJINT-2018-143
}

of gas nitriding. ${ }^{8)}$ Oxynitriding processes use air or steam at the end of the nitriding stage, while the complex oxide layer with $\mathrm{Fe}_{2} \mathrm{O}_{3}$ and $\mathrm{Fe}_{3} \mathrm{O}_{4}$ structures are formed on the surface. As a result, better properties including higher surface hardness and better corrosion resistance, can be obtained by oxynitriding than those traditional nitriding, due to the oxides of $\mathrm{Fe}_{3} \mathrm{O}_{4}$ and little $\mathrm{Fe}_{2} \mathrm{O}_{3}$. Moreover, the oxynitriding layer not only improves wear resistance but also the adhesive strength as an intermediate layer. ${ }^{8,9)}$

Diamond like carbon (DLC) has proven its outstanding tribological properties and surface hardness in many technical applications. DLC is a mixture of $\mathrm{sp}^{3}$ and $\mathrm{sp}^{2}$ bonded carbon atoms which are characteristic for diamond and graphite, respectively. The ratio of $\mathrm{sp}^{2} / \mathrm{sp}^{3}$ carbon atoms is one of the most import factors of the DLC films. DLC films are considered for widespread use as surface coating for wear protection. ${ }^{10,11)}$ In recent year's variety of methods such as ion beam, ion plating, sputtering and plasma enhanced chemical vapor deposition (plasma enhanced CVD) are used to deposit DLC films. Among these methods, plasma enhanced CVD is more suitable methods for surface modification of high speed steels used in various industries. ${ }^{7-9,12)}$ Besides, pulsed-DC is a recently developed plasma technology that controls the arcing during deposition 
and can reach higher deposition rates. This is due to the fact that pulsed-DC plasmas achieve higher power densities. ${ }^{13,14)}$ It is worth noting that the asymmetric bipolar pulsed-DC plasmas have been recently applied as an industrial solution to the deposition of DLC films by plasma enhanced CVD on large areas and with a high deposition rate. ${ }^{15,16)}$

Summarizing the above description, an oxynitride layer can significantly improve the adhesion of DLC films. Moreover, the characteristics and other properties of DLC films can be effectively improved by an asymmetric bipolar pulsed plasma enhanced CVD process; thus, the oxynitride/ DLC duplex treatment is utilized for treating PM30 steels in an attempt to increase tool life.

\section{Experimental Procedures}

PM30 steel was chosen as the substrate material to undergo a series of homogeneous heat treatments: the specimen was quenched at $1180^{\circ} \mathrm{C}$ and tempered at $560^{\circ} \mathrm{C}$ for $3 \mathrm{~h}$. This process was repeated 3 times to reach a hardness of $65 \pm 1$ HRC. A typical microstructure of PM30 steel was obtained through commercial heat treatment. The chemical compositions (mass\%) of PM30 steel are as follows: $1.28 \%$ C, $4.2 \% \mathrm{Cr}, 5.0 \% \mathrm{Mo}, 6.4 \% \mathrm{~W}, 3.1 \% \mathrm{~V}, 8.5 \% \mathrm{Co}$ and a balance of Fe. The heat-treated PM30 steel was then subjected to various surface treatments, including oxynitriding and a DLC coating after oxynitriding. The oxynitriding-treated specimens of PM30 steel were nitriding treated for $8 \mathrm{~h}$ at $550^{\circ} \mathrm{C}$ and then oxidized via steam for $60 \mathrm{~min}$ at $525^{\circ} \mathrm{C}$. Meanwhile, the value of undecomposed $\mathrm{NH}_{3}$ is kept at $25 \%$, and $\mathrm{H}_{2}$ is produced by the $75 \% \mathrm{NH}_{3}$ of dissociation during nitride-treatment. Moreover, the value of $\mathrm{H}_{2} \mathrm{O}$ volume is $5.56 \times 10^{-7} \mathrm{~m}^{3} \cdot \mathrm{s}^{-1}$ during oxide-treatment.

The DLC/oxynitride duplex treatments, in which oxynitriding was treated the same as the above-mentioned process, involved depositing a DLC coating onto oxynitride-treated PM30 steels. The DLC coating utilized the asymmetric bipolar-pulsed plasma enhanced CVD technology. Moreover, various $\mathrm{CH}_{4}$ gas flows with asymmetric bipolar-pulsed voltage $(-15+10 \%)$. To study the effects of different $\mathrm{CH}_{4}$ gas flows of the asymmetric bipolar-pulsed plasma enhanced CVD process, the positive-pulsed duty cycle was maintained at $10 \%$ and the negative-pulsed duty cycles were $15 \%$, respectively. The different $\mathrm{CH}_{4}$ gas flows of the bipolar-pulsed plasma enhanced CVD process are designated as $3,7,11,15$ and $19 \mathrm{sccm}$ (sccm may mean: standard cubic centimeter per minute, $1 \mathrm{sccm}=1.67 \times 10^{-8}$ $\left.\mathrm{m}^{3} \cdot \mathrm{s}^{-1}\right)$, hereafter. The surface of the specimens is cleaned with argon gas $(10 \mathrm{sccm})$. Furthermore, the coating time of the bipolar-pulsed plasma enhanced CVD was maintained at $90 \mathrm{~min}$; the frequency was $10 \mathrm{kHz}$; and input voltage was $150 \mathrm{~V}$, respectively. Meanwhile, $\mathrm{CH}_{4}$ gas was added at less than $1.33 \mathrm{~Pa}$ and continued for $90 \mathrm{~min}$, and followed by depositing of the DLC films.

In order to investigate the properties of DLC films for DLC/oxynitriding treated PM30 steel by the different $\mathrm{CH}_{4}$ gas flows of the asymmetric bipolar-pulsed plasma enhanced CVD, the Raman spectroscopy analysis (MOFiHR550), wear test (POD-FM800-25NT), indentation test (Indentec-8150LK), ${ }^{17)}$ nano-indentation (Hysitron TI 900) test and SEM (Hitachi-S4700) microstructure inspections were performed. The wear resistance of the specimens was evaluated in a ball-on-disk test (ASTM G99). The wear test parameters were as follows: the specimen size was $\emptyset 36 \times \mathrm{D} 5$

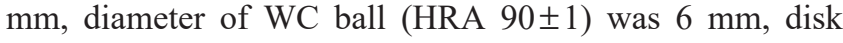
rotation was $200 \mathrm{rpm}$ and total rotation was 10000 revolutions, axial load was $2 \mathrm{~N}$ and $5 \mathrm{~N}$, and sliding speed of $0.25 \mathrm{~m} \cdot \mathrm{s}^{-1}$, respectively.

Additionally, corrosion potential analysis uses three electrodes method and follows by ASTM G59-97: the reference electrode is a saturated of silver-silver chloride electrode, auxiliary electrode uses a platinum electrode, and the working electrode is connected to the test specimens ${ }^{7,8)}$ The contact area of the specimen was $2.01 \mathrm{~cm}^{2}$. The corrosive solvent used 3.5 mass $\% \mathrm{NaCl}$ was maintained at room temperature. A scanning speed of $0.01 \mathrm{Vs}^{-1}$, initial potential of $-2.0 \mathrm{~V}$, and the final potential of $2.0 \mathrm{~V}$ were controlled. The polarization curve was obtained by Corr-View software to analyze and compare the corrosion potential $\left(\mathrm{E}_{\text {corr }}\right)$, corrosion current $\left(\mathrm{I}_{\text {corr }}\right)$ and polarization resistance $\left(\mathrm{R}_{\mathrm{p}}\right)$ of DLC/ oxynitriding-treated PM30 specimens.

\section{Results and Discussion}

Figure 1 shows the XRD pattern and surface hardness profile of optimal oxynitride-treated PM30 steel. The primary phases and structures of the oxynitride layer were $\mathrm{Fe}_{3} \mathrm{O}_{4}$ and $\mathrm{Fe}_{4} \mathrm{~N}$ ( $\gamma$ ' phase), as shown in Fig. 1(a). In general,
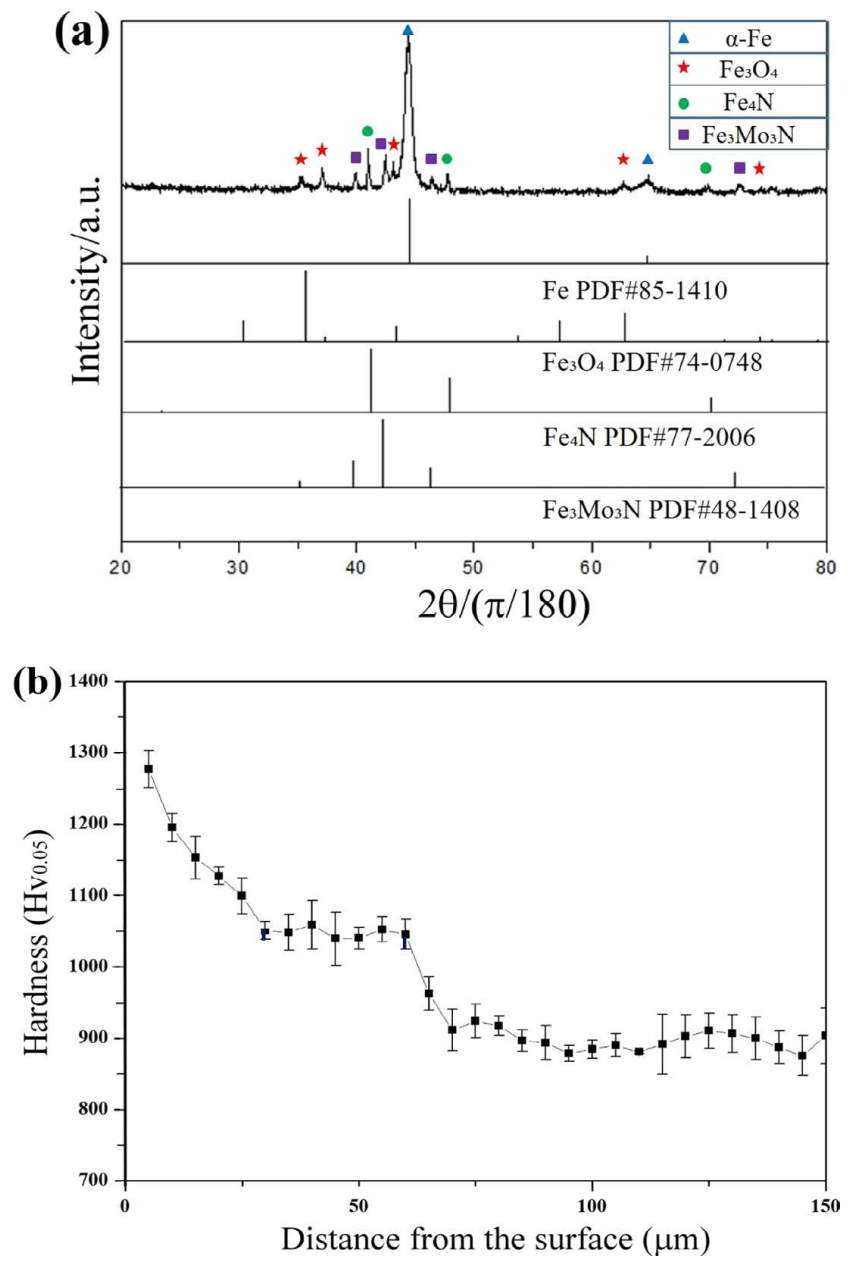

Fig. 1. XRD patterns and hardness test results of the oxynitriding treated PM30 steel. (Online version in color.) 
surface hardness does not only depend on the method of nitriding but also on the substrate material in which various phases were produced. The hardness of the iron nitrides $\left(\varepsilon-\mathrm{Fe}_{3} \mathrm{~N}\right.$ phase) was higher, whereas the hardness of the $\gamma^{\prime}-\mathrm{Fe}_{4} \mathrm{~N}$ phase was lower but possessed better ductility. ${ }^{18)}$ Furthermore, $\alpha-\mathrm{Fe}$ was the main element of the matrix for the PM30 steel and also appeared in the XRD patterns. Meanwhile, $\mathrm{Fe}_{3} \mathrm{Mo}_{3} \mathrm{~N}$ compounds were found. $\mathrm{Fe}_{3} \mathrm{Mo}_{3} \mathrm{~N}$ production is mainly caused by the high molybdenum content in PM30 steel (about 5.0\%). In the present research, neither a hard, brittle, nor dense structure of the $\delta$ - $\mathrm{Fe}_{2} \mathrm{~N}$ phase was found in the XRD pattern. It is reasonable to suggest that the wear properties would be significantly improved in the subsequent wear tests. Moreover, a complex oxynitride layer of $\mathrm{Fe}_{3} \mathrm{O}_{4}$ and $\mathrm{Fe}_{4} \mathrm{~N}$ structures was successfully formed on the surface. The oxynitride layer not only improved the wear and corrosion resistance, but also when acting as an intermediate layer, it was advantageous to the adhesive strength of DLC films. This result confirmed that the PM30 steel was successfully nitride-treated at $550^{\circ} \mathrm{C}$ for $8 \mathrm{~h}$ and oxide-treated at $525^{\circ} \mathrm{C}$ for $60 \mathrm{~min}$, and possessed a good oxynitriding layer and stable crystal structures.

Figure 1(b) represents the depth profile of the microhardness of the oxynitride-treated PM30 steel. The surface hardness was measured at an applied load of $0.49 \mathrm{~N}$ (approximately equal to $50 \mathrm{~g}$, expressed as $\mathrm{HV}_{0.05}$ in this study and tested at least three times) along the cross section of the test pieces with a micro-hardness tester (VMT-XT). Actually, the specimen's surface usually generated several types of nitrides and oxides after the oxynitriding treatment. When the specimen's surface possessed a higher concentration of oxide and nitrogen ions, a significant hardening effect of the atomic lattice strain appeared. As a result, the surface hardness of the specimen treated by the oxynitriding
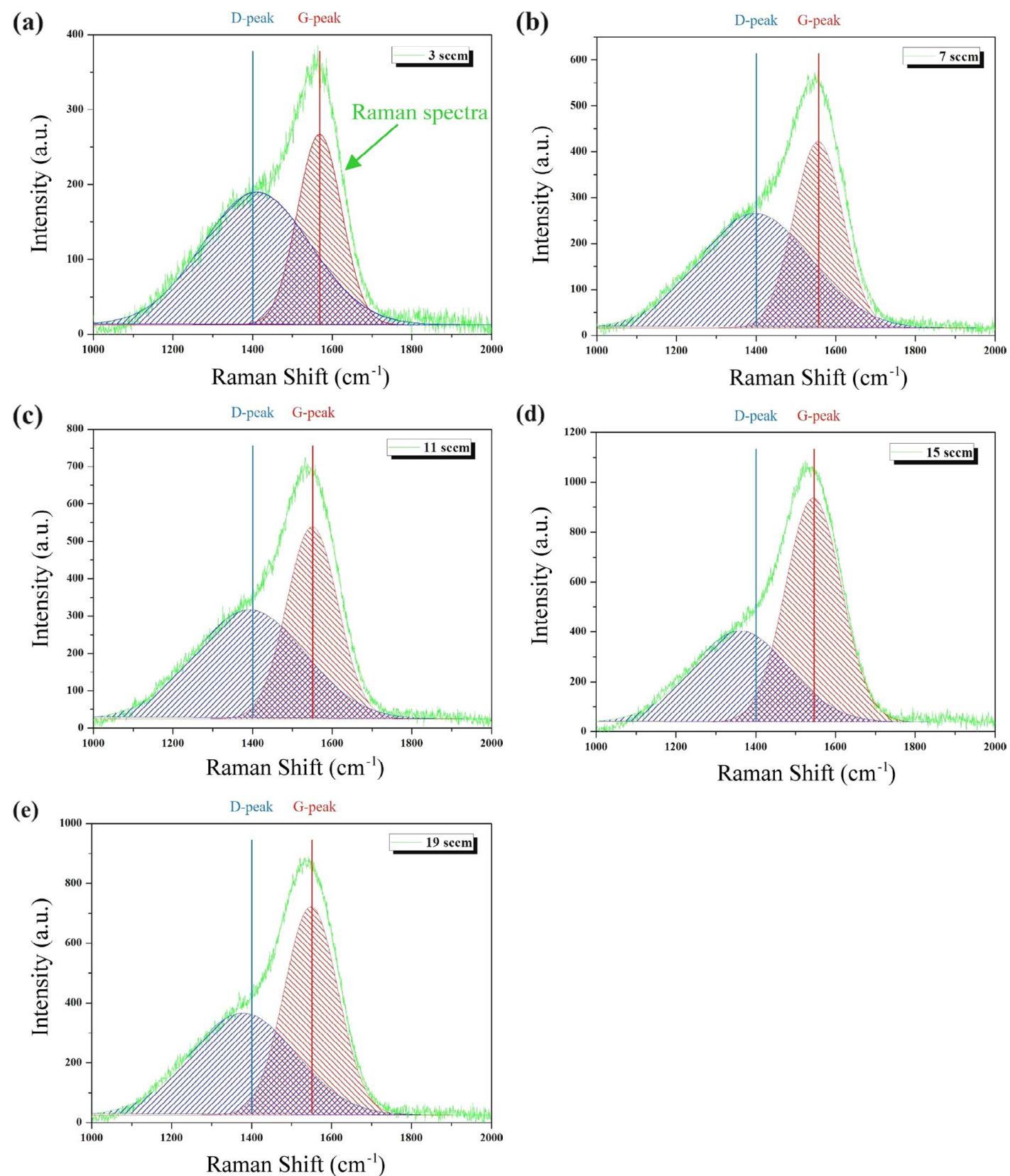

Fig. 2. Raman spectra of DLC fitted with double Gaussian peaks by different gas flow of asymmetric bipolar-pulsed plasma enhanced CVD. The green lines show the total fits, the red and blue lines show the Gaussian peaks corresponding to the G peak and D peak. (Online version in color.) 
process was elevated to $1277.5 \mathrm{HV}_{0.05}$. When the depth of the hardened layer was less than $28 \mu \mathrm{m}$, the hardness value was more than $1100.5 \mathrm{HV}_{0.05}$. At the same time, when the depth of the diffusion layer was 28-64 $\mu \mathrm{m}$, the hardness value was about 950-1 $050 \mathrm{HV}_{0.05}$. However, with an increase in the diffusion depth, the oxide and nitrogen concentrations were obviously reduced, which led to a decrease in hardness. The hardness reverted to the original hardness of the substrate (about $850.5 \mathrm{HV}_{0.05}$ ) after a depth of $64 \mu \mathrm{m}$, as seen in Fig. 1(b). Apparently, stable oxide $\left(\mathrm{Fe}_{3} \mathrm{O}_{4}\right)$ and nitride layers $\left(\mathrm{Fe}_{4} \mathrm{~N}\right)$ were successfully formed on the surface of the PM30 steel by the oxynitriding treatments, which led to an increase in the surface hardness of the specimen.

In general, Raman spectra of DLC samples were first treated with linear background removal and then, fitted with two Gaussian peaks simulating the D peak and G peak. ${ }^{19)}$ Figure 2 shows an example of a Raman spectrum fitted with two Gaussian peaks after background removal by different gas flows of asymmetric bipolar pulsed plasma enhanced CVD, while the Raman parameters of the $G$ peak and FWHM positions were calculated from the center position, and the $G$ peak was simulated by the standard deviation of the Gaussian function. As seen in Fig. 2, an apparent G peak and D peak appear on the Raman spectra. Normally, the $\mathrm{G}$ peak and D peak appear around 1580 and $1360 \mathrm{~cm}^{-1}$, respectively. In the experiment, almost all the G peaks and D peaks were similar to these values. It is reasonable to suggest that all specimens possessed the typical characteristics of DLC films.

In order to investigate the effects of the intermediate oxynitride layer, we consider our previous studies that have shown that the mechanical properties of DLC films are strongly affected by the hydrogen content, because hydrogen is a monovalent and acts to terminate potential carbon-carbon bonds. ${ }^{1,7,8)}$ An important potential benefit is that carbon clusters play a significant role in the growth of DLC films or crystalline diamonds. Furthermore, Gaussian function dismantling and synthesis are used to calculate the results of the integration area ratio $\left(\mathrm{I}_{\mathrm{D}} / \mathrm{I}_{\mathrm{G}}\right)$ and the offset of the $\mathrm{G}$ peak for the different gas flows of asymmetric bipolar pulsed plasma enhanced CVD. The previous literature has indicated a relationship between the $\mathrm{G}$ peak position, $\mathrm{I}_{\mathrm{D}} / \mathrm{I}_{\mathrm{G}}$, and $\mathrm{sp}^{3}$ content. ${ }^{20)}$ In this study, the evolution of the $\mathrm{G}$ peak position and $\mathrm{I}_{\mathrm{D}} / \mathrm{I}_{\mathrm{G}}$ ratio should be significant. The offset of the $\mathrm{G}$ peak can reveal the relative performance of the carbon films. As a result, a bulge in the Raman band occurred at $1500 \mathrm{~cm}^{-1}$, as shown in Fig. 3(a). However, the Raman spectra of the different gas flows did not show an obvious variation. Therefore, it was necessary to further analyze the synthesized peak decompositions to obtain the offset of the $\mathrm{G}$-peak position and the value of $\mathrm{I}_{\mathrm{D}} / \mathrm{I}_{\mathrm{G}}$. On the other hand, the full width at half maximum (FWHM) of the G-peak analysis could also be evaluated.

The emission spectroscopy of the plasma has been recognized to be an efficient diagnostic tool of the plasma parameters and for the monitoring of the chemical species present in the plasma processes used for the deposition of thin films. ${ }^{21)}$ However, the main parameters of the research are $\mathrm{CH}_{4}$ gas flow. Therefore, this study used the gas flow meters to control the $\mathrm{CH}_{4}$ gas. The $\mathrm{CH}_{4}$ gas is continuously input and output during the plasma enhanced CVD process.
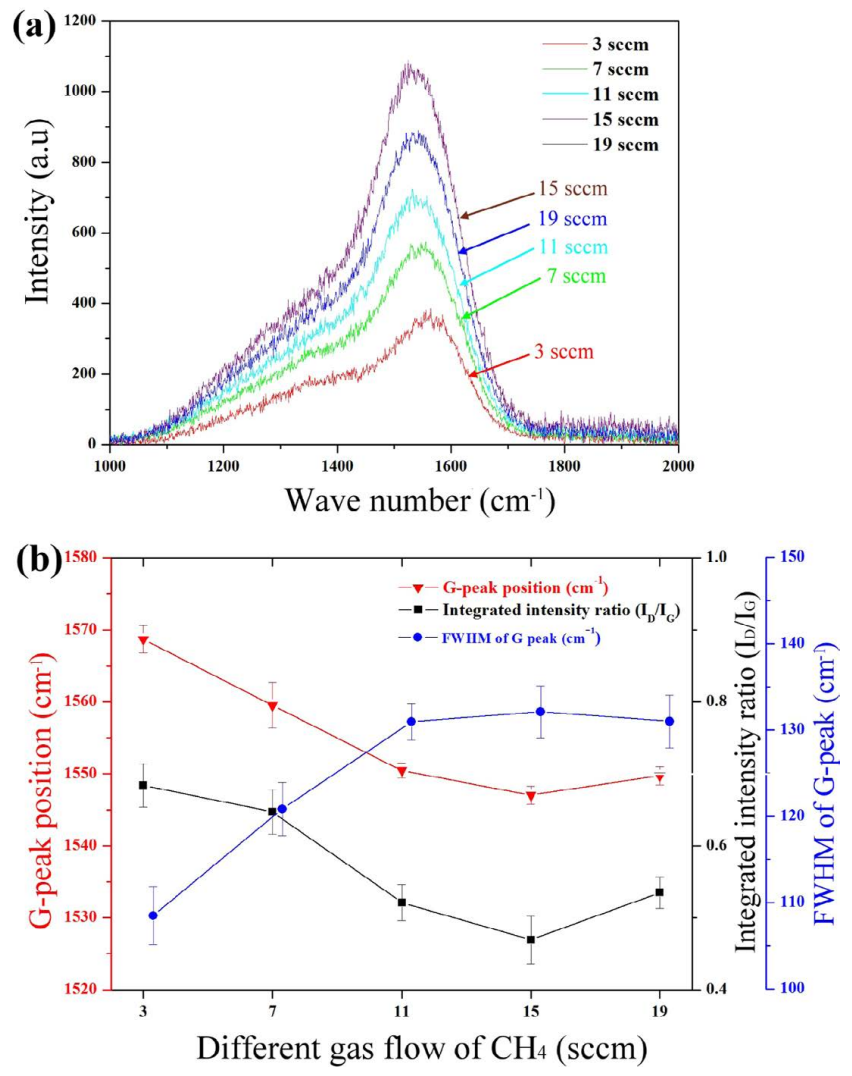

Fig. 3. Comparison of the (a) original Raman spectrum, and (b) G-peak position, $\mathrm{I}_{\mathrm{D}} / \mathrm{I}_{\mathrm{G}}$ and FWHM of G-peak analysis by different $\mathrm{CH}_{4}$ gas flow of asymmetric bipolar-pulsed plasma enhanced CVD. (Online version in color.)

Meanwhile, the vacuum is always maintained at $1.33 \mathrm{~Pa}$. Figure 3(b) reveals that the $3 \mathrm{sccm}$ possessed the highest value of $\mathrm{I}_{\mathrm{D}} / \mathrm{I}_{\mathrm{G}}(0.68)$, the smallest offset amount (1 568.7 $\left.\mathrm{cm}^{-1}\right)$ and an FWHM $\left(108.5 \mathrm{~cm}^{-1}\right)$ of the $\mathrm{G}$ peak. Upon the increase of the gas flow of the asymmetric bipolar pulsed plasma enhanced CVD, both the value of $\mathrm{I}_{\mathrm{D}} / \mathrm{I}_{\mathrm{G}}$ and the position of the $\mathrm{G}$ peak obviously declined, and then, rapidly rose, respectively. Conversely, the value of FWHM was obviously enhanced and then slightly decreased as the gas flow increased. As a result, the $15 \mathrm{sccm}$ possessed the lowest value of $\mathrm{I}_{\mathrm{D}} / \mathrm{I}_{\mathrm{G}}(0.47)$, the highest offset amount $\left(1547.1 \mathrm{~cm}^{-1}\right)$, and an FWHM $\left(132.1 \mathrm{~cm}^{-1}\right)$ of the G peak, respectively. Based on the relationship between $\mathrm{I}_{\mathrm{D}} / \mathrm{I}_{\mathrm{G}}$ and the size of the graphite planes, values of $\mathrm{I}_{\mathrm{D}} / \mathrm{I}_{\mathrm{G}}$ greater than unity are often found in a-C and $\mathrm{a}-\mathrm{C}: \mathrm{H}$. The presence of a large $\mathrm{D}$ component suggests that the $\mathrm{sp}^{2}$ cluster model is basically correct. ${ }^{8)}$ Besides, the $\mathrm{I}_{\mathrm{D}} / \mathrm{I}_{\mathrm{G}}$ ratio is often used to derive an $\mathrm{sp}^{2}$ correlation length for a-C(:H). It is reasonable to speculate that increasing the $\mathrm{I}_{\mathrm{D}} / \mathrm{I}_{\mathrm{G}}$ value resulted in the decrease in size of the diamond-like carbon film. Thus, it is possible to say with the increase in the gas flow from 3 to 15 sccm (the $\mathrm{I}_{\mathrm{D}} / \mathrm{I}_{\mathrm{G}}$ value decline), the size of the diamond-like carbon increases. However, increasing the gas flow from 15 to 19 (the $\mathrm{I}_{\mathrm{D}} / \mathrm{I}_{\mathrm{G}}$ value rose) causes the size of the diamondlike carbon to decrease. According to the above discussion and results, the $15 \mathrm{sccm}$ specimen relatively produced more stable $\mathrm{sp}^{3}$ bonds (lowest value of $\mathrm{I}_{\mathrm{D}} / \mathrm{I}_{\mathrm{G}}$, the highest offset amount and FWHM of G peak), with presumably better mechanical properties.

Increasing the $\mathrm{CH}_{4}$ gas flow can effectively enhance the 
amount of carbon elements and then, lead to DLC film production. However, a $\mathrm{CH}_{4}$ gas flow that is too high can easily cause many scattered carbon atoms. As a result, increasing the gas flow is not conducive to the formation of DLC films. This leads to a likelihood that the $\mathrm{sp}^{3}$ structure of the DLC films transformed to $\mathrm{sp}^{2}$ and further, affected the film's characteristics so that the DLC films gradually approached graphitization. Hence, the $15 \mathrm{sccm}$ possessed the lowest value of $\mathrm{I}_{\mathrm{D}} / \mathrm{I}_{\mathrm{G}}$ and the maximum offset amount of the $\mathrm{G}$ peak which is advantageous to the properties of the DLC films. These results can be further compared with our similar previous study on unbalanced bipolar pulsed plasma enhanced CVD. ${ }^{7)}$ It was found that the $15 \mathrm{sccm}$ of asymmetric bipolar pulsed plasma enhanced CVD $\left(\mathrm{I}_{\mathrm{D}} / \mathrm{I}_{\mathrm{G}}\right.$ of 0.47 and G-peak offset of $1547.1 \mathrm{~cm}^{-1}$ ) possess better DLC films, compared with the previous unbalanced bipolar pulsed plasma enhanced CVD $\left(\mathrm{I}_{\mathrm{D}} / \mathrm{I}_{\mathrm{G}}\right.$ of 0.52 and G-peak offset of $\left.1542.7 \mathrm{~cm}^{-1}\right)$. $^{7}$ ) Thus, it is reasonable to surmise that the present research with asymmetric bipolar pulsed DLC films produced more carbon atoms to form an $\mathrm{sp}^{3}$ bond with other carbon atoms. Meanwhile, due to the increase in the $\mathrm{sp}^{3}$ bonds, the $\mathrm{sp}^{2}$ bonds were reduced to a critical value, which mitigated the G-peak offset. This finding was consistent with our previous study. ${ }^{1,7)}$

Figure 4 shows the SEM images of loading impact tests (Rockwell C scale indentation) for various gas flows of the asymmetric bipolar pulsed plasma enhanced CVD process.
All specimens had similar surface features after the loading impact test. Almost no significant peeling-off phenomenon was generated, as seen in Figs. 4(a)-4(e). Typically, the adhesion strength of DLC films on high speed steel is poor, but the adhesion-enhancing materials have been used directly as intermediate layers. In our research, pre-treated PM30 steel was used in the oxynitriding process as an intermediate layer. The nitrogen and oxide atoms entered the interstices of the lattice via atomic diffusion, easily resulting in lattice deformation and surface hardening. Apparently, the intermediate layer plays an important role in enhancing the adhesion of DLC films. Besides, our previous study indicated that the asymmetric bipolar pulsed treatment was more effective in slowing down the particle impact. ${ }^{7}$ Whereby, the DLC films produced more carbon atoms to form the $\mathrm{sp}^{3}$ structures and bond with other carbon atoms. According to the standard of the VDI 3198 indentation test, ${ }^{17)}$ that indicates that the DLC films under different $\mathrm{CH}_{4}$ gas flows have good adhesion, all specimens belong to the HF 1-2 grades.

Figure 5 shows the hardness and elastic modulus of DLC/ oxynitriding film using different gas flows of asymmetric bipolar pulsed plasma enhanced CVD. Clearly, increasing the $\mathrm{CH}_{4}$ gas flow caused both the value of the hardness and elastic modulus to rise noticeably and then, rapidly decline. As seen in Fig. 5, when the $\mathrm{CH}_{4}$ gas flow rose to $15 \mathrm{sccm}$, the optimum hardness $(5.91 \mathrm{GPa})$ and the highest elastic modulus $(89.87 \mathrm{GPa})$ were obtained. However, when the
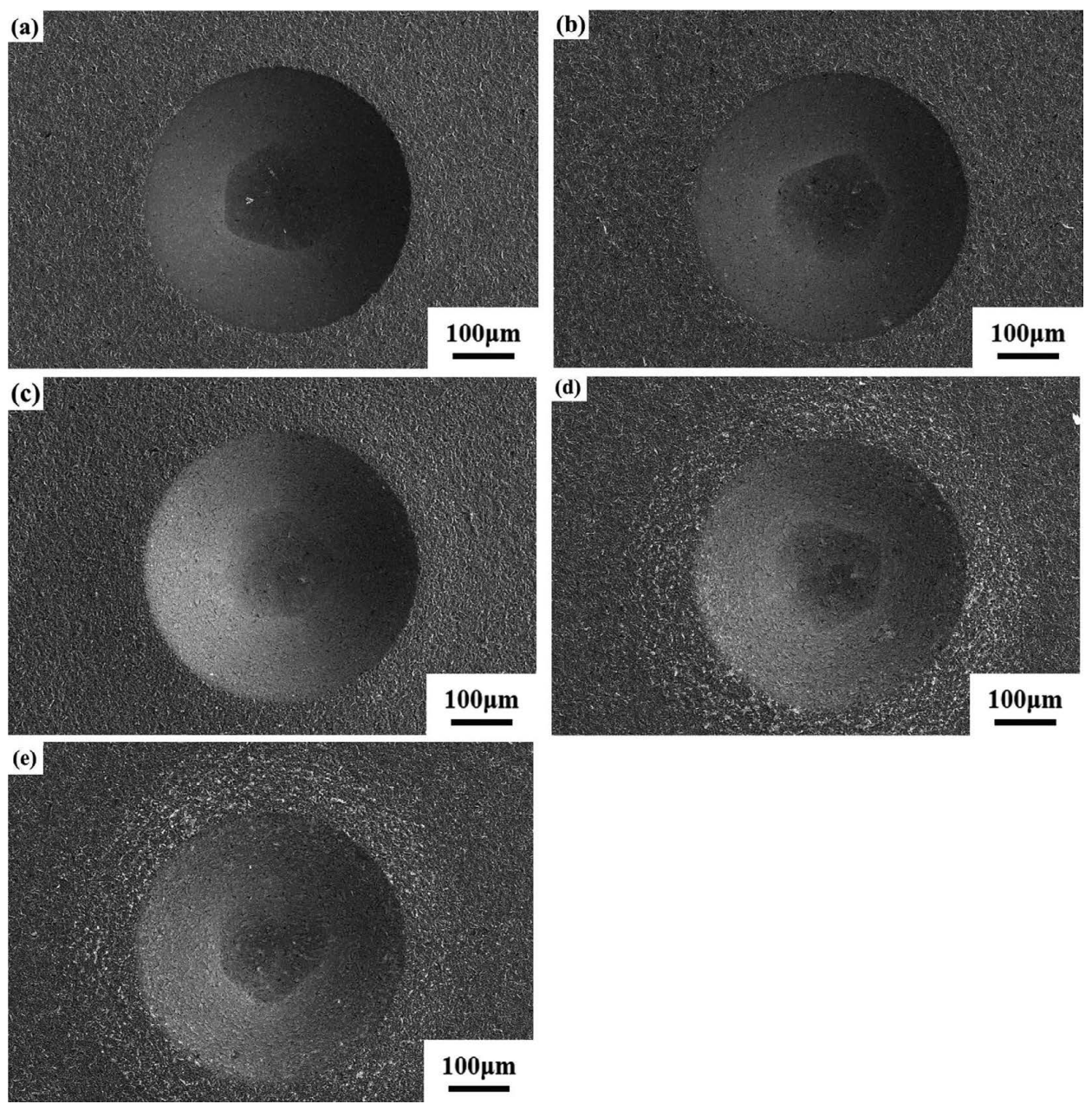

Fig. 4. SEM images of the loading impact test by the various $\mathrm{CH}_{4}$ gas flow of asymmetric bipolar-pulsed plasma enhanced CVD: (a) $3 \mathrm{sccm}$, (b) $7 \mathrm{sccm}$, (c) $11 \mathrm{sccm}$, (d) $15 \mathrm{sccm}$, and (e) $19 \mathrm{sccm}$. 


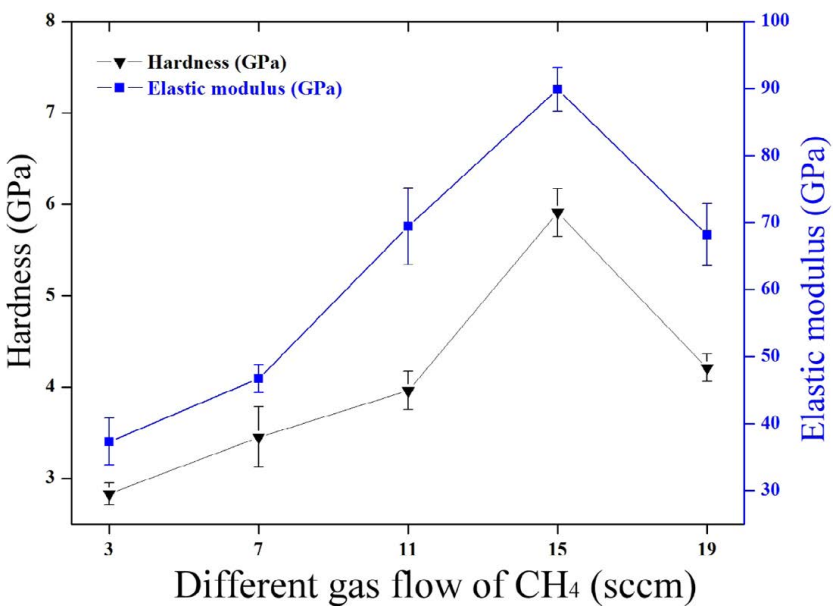

Fig. 5. Comparison of the hardness and elastic modulus of DLC/ oxynitriding film by different $\mathrm{CH}_{4}$ gas flow of asymmetric bipolar-pulsed plasma enhanced CVD. (Online version in color.)

$\mathrm{CH}_{4}$ gas flow increased more than $15 \mathrm{sccm}$, the hardness and elastic modulus dramatically declined $(4.21 \mathrm{GPa}$ and 68.14 GPa, respectively). Since hydrogen-containing amorphous DLC films are more sensitive to the energy of sedimentary ions, under the appropriate ion bombardment and gas reaction, the micro-cracks inside the DLC films were reduced and the deposited density increased.

Additionally, when the $\mathrm{CH}_{4}$ gas flow was $3 \mathrm{sccm}$, the energy obtained by each ion was greater. Hence, the bombardment energy of the surface was too strong. As a result, the $\mathrm{sp}^{3}$ structure easily transformed to an $\mathrm{sp}^{2}$ structure, thus resulting in lower hardness and elastic modulus $(2.83 \mathrm{GPa}$ and $38.28 \mathrm{GPa}$, respectively). Increasing the $\mathrm{CH}_{4}$ gas flow is effective in enhancing the reaction rate between carbon and carbon, thereby improving the deposition and densification of the DLC films. An excessive $\mathrm{CH}_{4}$ gas flow can not help to DLC films, it affected the formation of the DLC coating instead. Apparently, an appropriate gas flow is helpful in enhancing the hardness and elastic modulus of DLC films because of the asymmetric bipolar pulsed plasma enhanced CVD. Compared with Fig. 3, this result is consistent with our discussion and findings above.

In engineering practice, low friction means lower loss of energy, high reliability, and better wear resistance. As previously noted, DLC films possess superior tribological characteristics correlated to the fraction of $\mathrm{sp}^{3}$ bonds in the films, such as a low friction coefficient and high wear resistance. The volume loss in the wear tests allows the wear rate of the material to be calculated. Figure 6 shows the wear loss volume and specific wear rate for different gas flows of asymmetric bipolar pulsed plasma enhanced CVD. Among them, Fig. 6(a) illustrates that the wear loss volume displayed an obvious decrease and then an increase as the $\mathrm{CH}_{4}$ gas flow was increased. The lowest wear volume value $\left(3.82 \times 10^{-3} \mathrm{~mm}^{3}\right)$ occurred at the power density of $15 \mathrm{sccm}$ after the lower load $(2 \mathrm{~N})$ of the wear tests.

Because the DLC film is metastable amorphous carbon materials with $\mathrm{sp}^{3}$ and $\mathrm{sp}^{2}$ bonds, its superior tribological characteristics correlated to the fraction of $\mathrm{sp}^{3}$ bonds in the films. Thus, it is possible to say that the DLC films at a gas flow of $3 \mathrm{sccm}$ exhibited an unstable $\mathrm{sp}^{3} / \mathrm{sp}^{2}$ structure, which
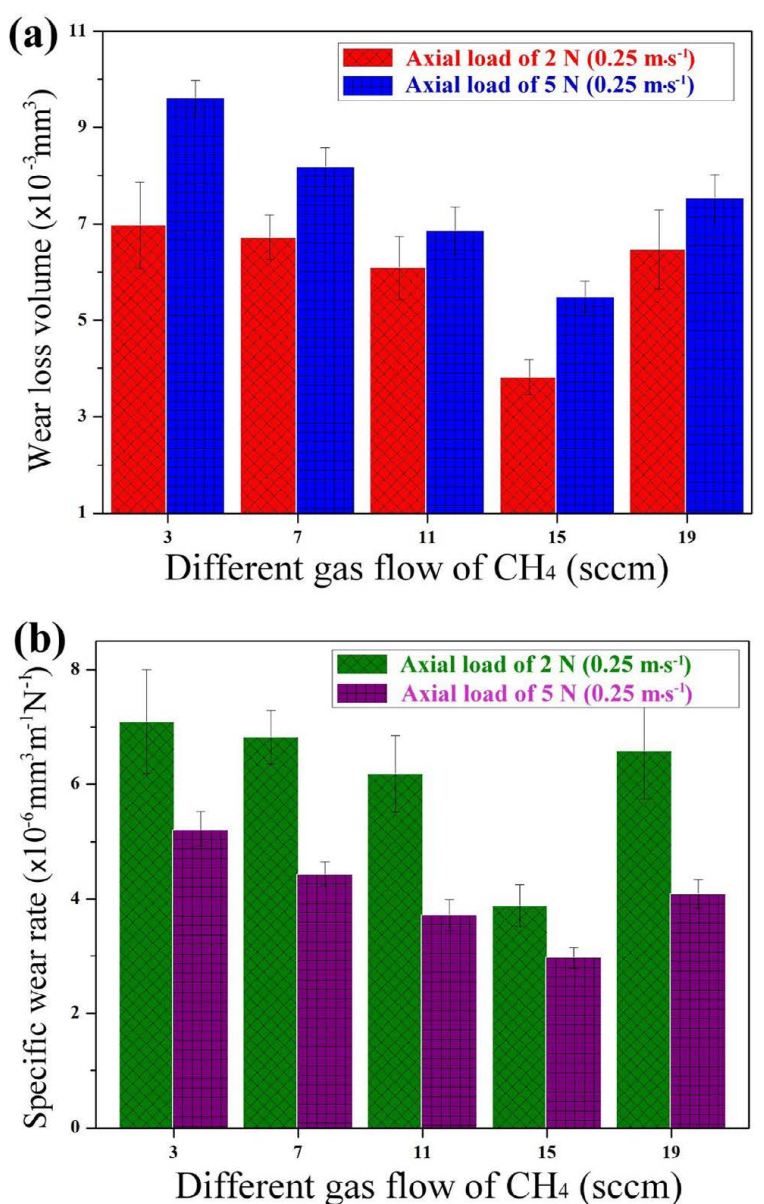

Fig. 6. Comparison of the wear volume loss of the different $\mathrm{CH}_{4}$ gas flow of asymmetric bipolar-pulsed plasma enhanced CVD: (a) load $2 \mathrm{~N}$ and sliding speed $0.25 \mathrm{~m} \cdot \mathrm{s}^{-1}$, and (b) load $5 \mathrm{~N}$ and sliding speed $0.25 \mathrm{~m} \cdot \mathrm{s}^{-1}$. (Online version in color.)

was represented in the wear test results. The highest wear loss volume $\left(6.95 \times 10^{-3} \mathrm{~mm}^{3}\right)$ occurred at a gas flow of $3 \mathrm{sccm}$. In order to further investigate the effect of different axial loads on the self-lubricating properties of a DLC film, as the axial load increased $(2 \rightarrow 5 \mathrm{~N})$, the wear loss volume of all specimens under different gas flows increased dramatically compared with a low axial load $(2 \mathrm{~N})$, as also shown in Fig. 6(a). The lowest wear loss volume $\left(5.49 \times 10^{-3}\right.$ $\mathrm{mm}^{3}$ ) appeared in the gas flow of $15 \mathrm{sccm}$ at a higher load $(5 \mathrm{~N})$, while the highest value for wear loss volume $(9.57 \times$ $10^{-3} \mathrm{~mm}^{3}$ ) was at a gas flow of $3 \mathrm{sccm}$ after the wear test $(5 \mathrm{~N})$. These results are consistent with previous hardness tests (as see in Fig. 5). Significantly, the $15 \mathrm{sccm}$ specimen possessed optimal wear resistance under the different loads of the wear tests.

Generally speaking, the specific wear rate is defined as the wear volume loss per unit distance per unit load. Clearly, all the specific wear rates under a high axial load $(5 \mathrm{~N})$ were lower than those under a low axial load $(2 \mathrm{~N})$ for the different $\mathrm{CH}_{4}$ gas flows, as shown in Fig. 6(b). Previous literature indicated that higher thermal energy easily caused the DLC structure to be transformed into a graphite structure. ${ }^{22)}$ In this work, the specimen's surface generated a higher energy under a high axial load in the wear process, which likely resulted in the graphitization phenomenon of the DLC film and caused the $\mathrm{sp}^{3}$ to transform into an 
$\mathrm{sp}^{2}$ bond. As a result, the wear resistance was obviously improved by the self-lubricating effect of the graphite. In other words, the high axial load specimens possessed a relatively lower specific wear rate. This result confirmed the relationship between the high energy and graphitization phenomenon of the DLC films. The lowest specific wear rate of $2.97 \times 10^{-6} \mathrm{~mm}^{3} \mathrm{~m}^{-1} \cdot \mathrm{N}^{-1}(5 \mathrm{~N})$ appeared at a gas flow of $15 \mathrm{sccm}$. Conversely, the highest specific wear rate of $7.05 \times 10^{-6} \mathrm{~mm}^{3} \mathrm{~m}^{-1} \cdot \mathrm{N}^{-1}(2 \mathrm{~N})$ appeared at a gas flow of $3 \mathrm{sccm}$. According to the above discussion and results, we were able to further confirm that at a gas flow of 15 sccm the asymmetric bipolar pulsed plasma enhanced CVD resulted in DLC films with good adhesion strength and optimal wear resistance.

Figure 7 shows the SEM surface morphology of the wear test under a load of $2 \mathrm{~N}$ and a sliding speed of $0.25 \mathrm{~m} \cdot \mathrm{s}^{-1}$ after different gas flows of the asymmetric bipolar pulsed plasma enhanced CVD. The specimen of the $3 \mathrm{sccm}$ generated a little spalling phenomenon between the DLC/ oxynitride films and the PM30 substrate which displayed wide and deep wear tracks. As seen in Fig. 7(a), the gas flow of $3 \mathrm{sccm}$ produced the widest wear tracks $(252.03 \mu \mathrm{m})$. With the increase in $\mathrm{CH}_{4}$ gas flow $(7 \rightarrow 9 \rightarrow 11 \mathrm{sccm})$, the wear resistance effectively improved and the wear width narrowed obviously, as shown in Figs. 7(b)-7(d). It was found that a gas flow of $15 \mathrm{sccm}$ possessed the narrowest wear tracks $(138.02 \mu \mathrm{m})$, as shown in Fig. 7(d). However, a $\mathrm{CH}_{4}$ gas flow that was too high $(19 \mathrm{sccm})$ easily resulted in an unstable $\mathrm{sp}^{3}$ structure and a lower hardness. Thus, the wear tracks represent a relatively wide and deep morphology, as shown in Fig. 7(e). It is reasonable to say that the specimens of $15 \mathrm{sccm}$, with more $\mathrm{sp}^{3}$ bonding and stable DLC structures, resulted in good adhesion strength and wear resistance.

Figure 8 shows the SEM surface morphology of the wear test under a higher load of $5 \mathrm{~N}$ and a sliding speed of $0.25 \mathrm{~m} \cdot \mathrm{s}^{-1}$ for the different gas flows of asymmetric bipolar pulsed plasma enhanced CVD. Figures 8(a) and 8(b) represent relatively wide tracks, while Fig. 8(c) displayed significantly deep wear tracks. In addition, obvious DLC micro-cracks appeared in Figs. 8(a), 8(c) and 8(e) (indicated by the arrows). Among them, the gas flow of $3 \mathrm{sccm}$ generated a dramatically spalling phenomenon between the DLC/ oxynitride films and the PM30 substrate, as shown in Fig. 8(a). In addition, the DLC/oxynitride films produced a slight peeling phenomenon and micro-cracks after gas flows of 11 and $19 \mathrm{sccm}$, as shown in Figs. 8(c) and 8(e). Besides, the DLC/oxynitride films produced a dramatic peeling phenomenon and micro-cracks after the lowest and highest gas flow of 3 and 19 sccm, as shown in Figs. 8(a) and 8(d). However, the surface morphology showed relatively narrow tracks and almost no abrasion damage at a gas flow of $15 \mathrm{sccm}$,
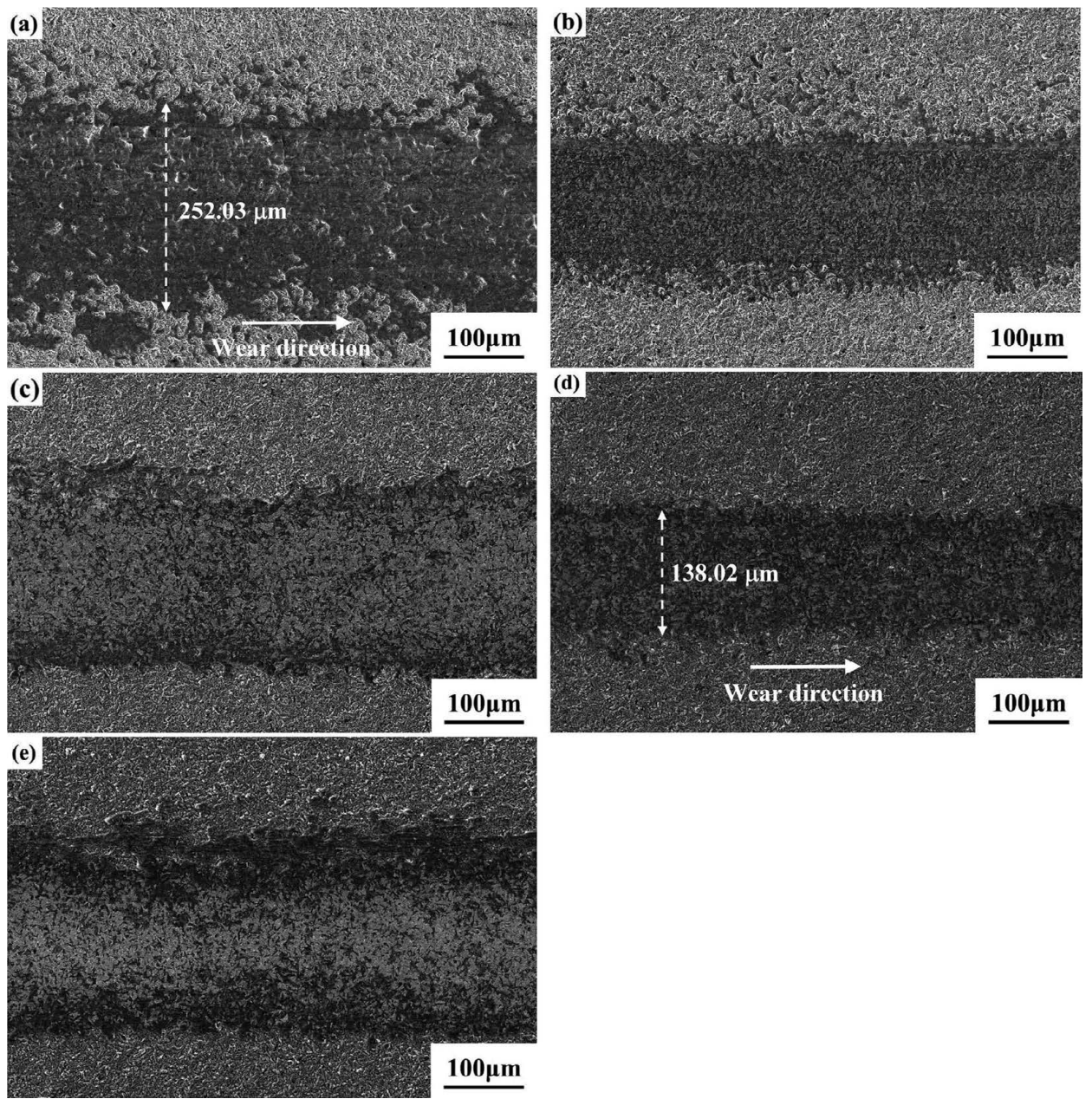

Fig. 7. Surface morphology observations of wear test (sliding speed $0.25 \mathrm{~m} \cdot \mathrm{s}^{-1}$ and load $2 \mathrm{~N}$ ) by the different $\mathrm{CH}_{4}$ gas flow of asymmetric bipolar-pulsed plasma enhanced CVD: (a) $3 \mathrm{sccm}$, (b) $7 \mathrm{sccm}$, (c) $11 \mathrm{sccm}$, (d) $15 \mathrm{sccm}$, and (e) $19 \mathrm{sccm}$. 

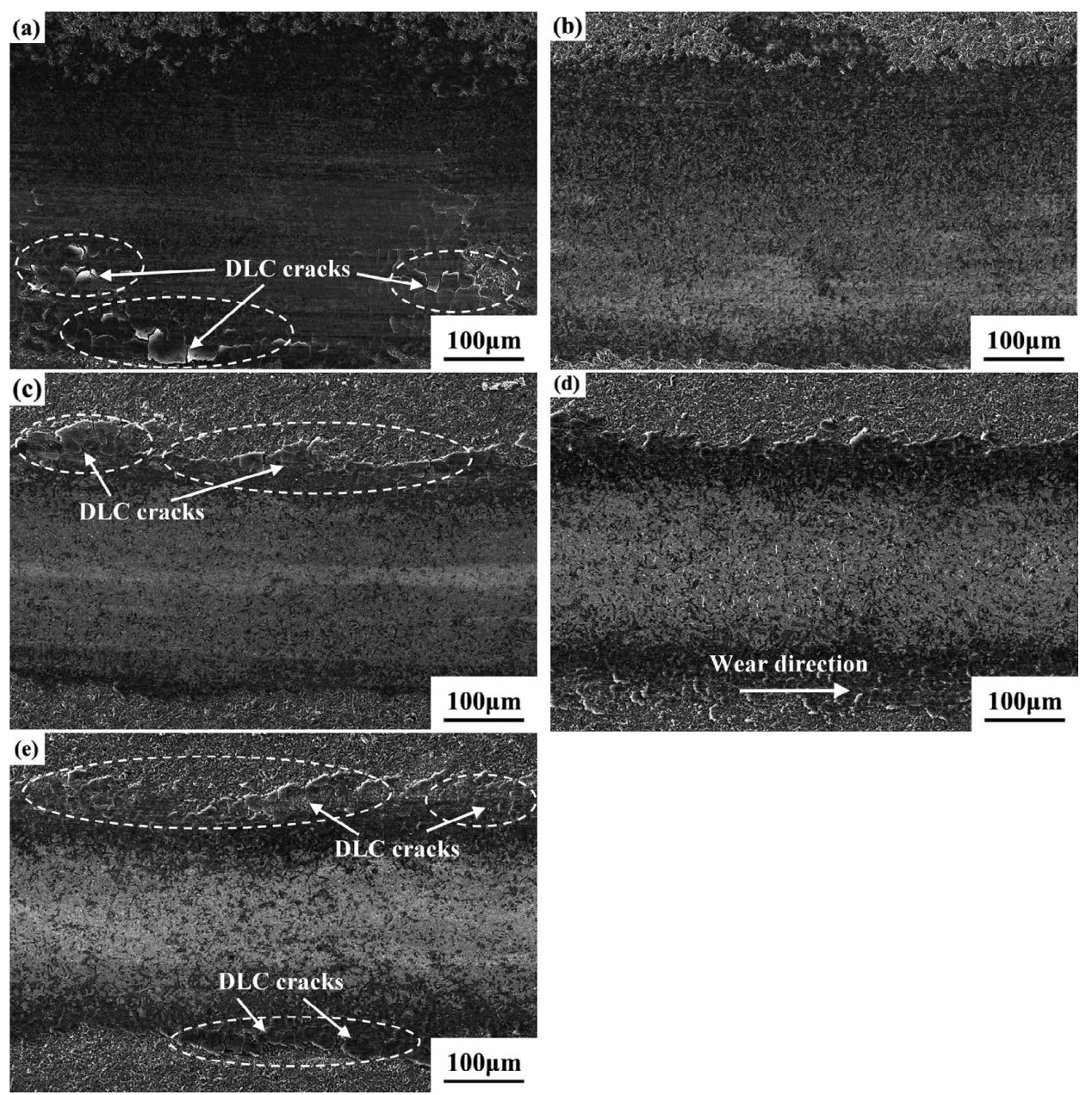

Fig. 8. Surface morphology observations of wear test (sliding speed $0.25 \mathrm{~m} \cdot \mathrm{s}^{-1}$ and load $5 \mathrm{~N}$ ) by the different $\mathrm{CH}_{4}$ gas flow of asymmetric bipolar-pulsed plasma enhanced CVD: (a) $3 \mathrm{sccm}$, (b) $7 \mathrm{sccm}$, (c) $11 \mathrm{sccm}$, (d) $15 \mathrm{sccm}$, and (e) $19 \mathrm{sccm}$.

as shown in Fig. 8(d). As previously discussed, a too-low or too-high $\mathrm{CH}_{4}$ gas flow usually generated an unstable gas reaction and $\mathrm{sp}^{3}$ structures, which easily resulted in both a low content of $\mathrm{sp}^{3}$ carbon and a structure under a plasma atmosphere. Therefore, it was reasonable to surmise that the gas flow of $15 \mathrm{sccm}$, with more $\mathrm{sp}^{3}$ bonding and a stable DLC structure, resulted in good adhesion strength and wear resistance. This also agrees with our previous discussion.

DLC films have attracted significant attention recently due to their low friction, high hardness, high elastic modulus, corrosion resistance, biocompatibility, and high degree of wear resistance. In the present research, the corrosion behavior of the DLC films was an important concern. Figure 9 shows the Tafel slope results of the PM30 specimens for various gas flows of asymmetric bipolar pulsed plasma enhanced CVD after the 3.5 mass $\% \mathrm{NaCl}$ corrosion test. All specimens possessed an obvious passivation phenomenon. Since the passivation layer generated a protective effect, our previous studies indicated that the samples with a lower corrosion current ( $\mathrm{I}_{\text {corr }}$ ) and a higher polarization resistance $\left(\mathrm{R}_{\mathrm{p}}\right)$ evidenced better corrosion resistance. ${ }^{1,7,8)} \mathrm{A}$ comparison of the corrosion resistance $\left(I_{\text {corr }}, E_{\text {corr }}\right.$ and $R_{p}$ ) for the different $\mathrm{CH}_{4}$ gas flows of the DLC/oxynitride-treated PM30 specimens is shown in Table 1. The lowest corrosion current $\left(1.43 \times 10^{-4} \mathrm{~A} \cdot \mathrm{cm}^{-2}\right)$ and highest polarization resistance $\left(5.32 \times 10^{2} \Omega \cdot \mathrm{cm}^{2}\right)$ of the DLC/oxynitride-

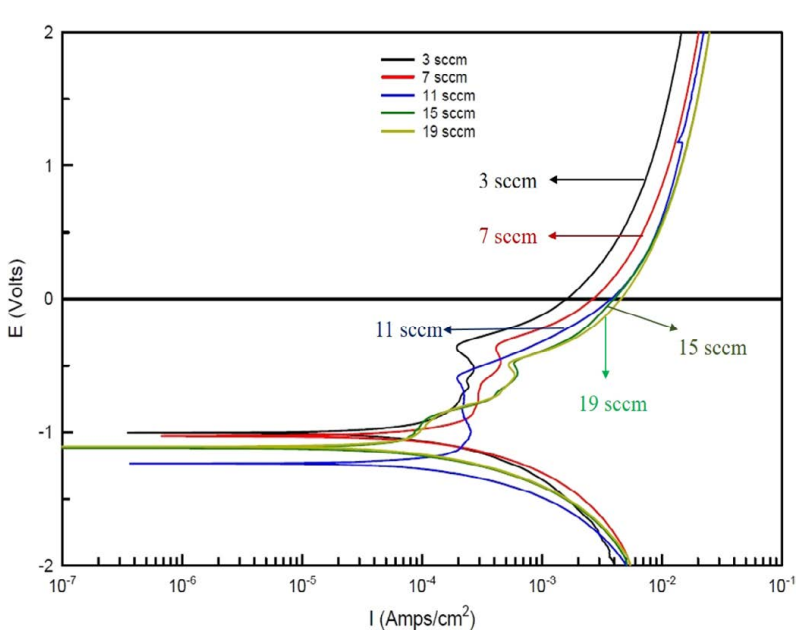

Fig. 9. Tafel results of PM30 specimens by different $\mathrm{CH}_{4}$ gas flow of asymmetric bipolar-pulsed plasma enhanced CVD after $3.5 \mathrm{wt} \% \mathrm{NaCl}$ corrosion test. (Online version in color.)

treated PM30 specimens appeared at a gas flow of $15 \mathrm{sccm}$, while the $3 \mathrm{sccm}$ specimen possessed the highest corrosion current $\left(3.89 \times 10^{-4} \mathrm{~A} \cdot \mathrm{cm}^{-2}\right)$ and the lowest polarization resistance $\left(2.48 \times 10^{2} \Omega \cdot \mathrm{cm}^{2}\right)$. These results reveal that the $15 \mathrm{sccm}$ specimen had a relatively stable $\mathrm{sp}^{3} / \mathrm{sp}^{2}$ bonding structure, which helped improve corrosion resistance.

Increasing the $\mathrm{CH}_{4}$ gas flow $(3 \rightarrow 7 \rightarrow 11 \rightarrow 15 \mathrm{sccm})$ 
Table 1. Comparison of the corrosion resistance of PM30 specimens by various $\mathrm{CH}_{4}$ gas flow of asymmetric bipolar-pulsed plasma enhanced CVD after $3.5 \mathrm{wt} \% \mathrm{NaCl}$ corrosion test.

\begin{tabular}{cccc}
\hline Specimens & $\mathrm{I}_{\text {corr }}\left(\times 10^{-4} \mathrm{~A} \cdot \mathrm{cm}^{-2}\right)$ & $\mathrm{E}_{\text {corr }}($ Volts $)$ & $\mathrm{R}_{\mathrm{p}}\left(\times 10^{2} \Omega \cdot \mathrm{cm}^{2}\right)$ \\
\hline $3 \mathrm{sccm}$ & 3.89 & -1.01 & 2.48 \\
$7 \mathrm{sccm}$ & 1.98 & -1.03 & 3.35 \\
$11 \mathrm{sccm}$ & 1.93 & -1.23 & 3.75 \\
$15 \mathrm{sccm}$ & 1.43 & -1.12 & 5.32 \\
$19 \mathrm{sccm}$ & 2.03 & -1.10 & 5.03 \\
\hline
\end{tabular}

effectively contributes to the reaction rate of the gas and the generation of carbon atoms. As a result, more stable $\mathrm{sp}^{3} / \mathrm{sp}^{2}$ structures were formed, leading to a better corrosion resistance. As seen in Table 1, as the $\mathrm{CH}_{4}$ gas flow increased, the corrosion current decreased slightly $(3.89 \rightarrow 1.98 \rightarrow$ $\left.1.93 \rightarrow 1.43 \times 10^{-4} \mathrm{~A} \cdot \mathrm{cm}^{-2}\right)$ and the polarization resistance increased noticeably $(2.48 \rightarrow 3.35 \rightarrow 3.75 \rightarrow 5.32 \times$ $\left.10^{2} \Omega \cdot \mathrm{cm}^{2}\right)$, respectively. However, an excessive $\mathrm{CH}_{4}$ gas flow $(19 \mathrm{sccm})$ caused a scattered gas reaction, and unstable $\mathrm{sp}^{3}$ and loose $\mathrm{sp}^{2}$ structures, reducing corrosion resistance. As a result, the corrosion current increased dramatically and the polarization resistance declined slightly. In spite of the DLC films possessing excellent chemical inertness, the $\mathrm{sp}^{2}$ bonding generally accelerated the electro-migration between the substrate and etching solutions, which resulted in an increase in current density and a reduction in corrosion resistance. Only more stable $\mathrm{sp}^{3}$ bonding structures could produce DLC films possessing good corrosion resistance. As seen in Fig. 1, oxynitride-treated PM30 steel clearly formed a passive film $\left(\mathrm{Fe}_{3} \mathrm{O}_{4}\right.$ structures), which contributed to a better anti-corrosion property during the corrosion test. Consequently, the stable DLC structures and oxide layers of the DLC/oxynitride films were essential to improve the corrosion resistance. According to the above discussion and results, the $15 \mathrm{sccm}$ specimen of the asymmetric bipolar pulsed plasma enhanced CVD possessed optimal tribological properties and corrosion resistance.

\section{Conclusions}

The experimental results show that DLC thin films were successfully obtained after PM30 steel was treated using the DLC/oxynitriding duplex treatment. In this study, the optimal $\mathrm{CH}_{4}$ gas flow of the asymmetric bipolar pulsed plasma enhanced CVD for PM30 steel was $15 \mathrm{sccm}$. Increasing the $\mathrm{CH}_{4}$ gas flow ( $3 \rightarrow 15 \mathrm{sccm}$ ) effectively contributed to the reaction rate of the gas and the generation of carbon atoms. As a result, more stable $\mathrm{sp}^{3} / \mathrm{sp}^{2}$ structures formed leading to better wear and corrosion resistance. However, excessive $\mathrm{CH}_{4}$ gas flow (19 sccm) likely caused the scattered gas reaction, which resulted in unstable $\mathrm{sp}^{3}$ and loose $\mathrm{sp}^{2}$ structures. Thus, the $\mathrm{I}_{\mathrm{D}} / \mathrm{I}_{\mathrm{G}}$ values were increased, reducing the wear and corrosion resistance.
In the present research, the lowest $\mathrm{I}_{\mathrm{D}} / \mathrm{I}_{\mathrm{G}}(0.47)$, the greatest offset $\left(1547.1 \mathrm{~cm}^{-1}\right)$, and the FWHM $\left(132.1 \mathrm{~cm}^{-1}\right)$ of the $\mathrm{G}$ peak appeared in a $\mathrm{CH}_{4}$ gas flow of $15 \mathrm{sccm}$. Simultaneously, the highest hardness $(5.91 \mathrm{GPa})$ and elastic modulus $(89.87 \mathrm{GPa})$ were obtained, resulting in the lowest wear loss volume and the lowest specific wear rate (load of 2 and $5 \mathrm{~N}$, respectively). Significantly, $\mathrm{CH}_{4}$ gas flow of 15 sccm possesses stable $\mathrm{sp}^{3} / \mathrm{sp}^{2}$ bonding and better structure, as well as good adhesion strength and wear resistance. In addition, the specimen possesses a relatively low corrosion current $\left(1.43 \times 10^{-4} \mathrm{~A} \cdot \mathrm{cm}^{-2}\right)$ and high polarization resistance $\left(5.32 \times 10^{2} \Omega \cdot \mathrm{cm}^{2}\right)$. Consequently, the study results confirmed that the optimal wear and corrosion resistance of PM30 high speed steel is effectively improved through the asymmetric bipolar pulsed plasma enhanced CVD-treated DLC/oxynitriding duplex treatment.

\section{Acknowledgments}

The experimental equipment is supported by the Department of Chemical and Material Engineering Lunghwa University of Science and Technology, and ASSAB STEELS TAIWAN CO., LTD.

\section{REFERENCES}

1) S. H. Chang, C. L. Huang, K. T. Huang and C. M. Liu: ISIJ Int., 56 (2016), 2276.

2) G. M. Bedforda, V. I. Vitanov and I. I. Voutchkovc: Surf. Coat. Technol., 141 (2001), 34.

3) ASSAB PM 30 SuperClean, ASSAB Steel Website, http://www. assab-japan.com/media/ASSAB PM 30 SuperClean Brochure English.pdf, (accessed 2016-07-26).

4) B. G. Wendler: Surf. Coat. Technol., 100-101 (1998), 276

5) J. Ma, B. Wang, Z. L. Yang, G. X. Wu, J. Y. Zhang and S. L. Zhao: Int. J. Miner. Metall. Mater., 23 (2016), 294.

6) P. Panjan, M. Čekada, M. Panjan, D. Kek-Merl, F. Zupanič, L. Čurkovič and S. Paskvale: Vacuum, 86 (2012), 794.

7) S. H. Chang, C. C. Yu, K. T. Huang and C. M. Liu: ISIJ Int., 55 (2015), 2631.

8) S. H. Chang, W. C. Wu, K. T. Huang and C. M. Liu: Mater. Trans., 58 (2017), 806.

9) S. H. Chang, Y. K. Lin and K. T. Huang: Surf. Coat. Technol., 207 (2012), 571.

10) J. Heeg, M. Rosenberg, C. Schwarz, T. Barfels and M. Wienecke: Vacuum, 83 (2008), 712.

11) M. H. Ahmed, J. A. Byrne and J. McLaughlin: Surf. Coat. Technol., 209 (2012), 8.

12) K. N. Pandiyaraj, V. Selvarajan, J. Heeg, F. Junge, A. Lampka, T. Barfels, M. Wienecke, Y. H. Rhee and H. W. Kim: Diam. Relat. Mater., 19 (2010), 1085.

13) C. Corbella, M. Vives, G. Oncins, C. Canal, J. L. Andújar and E. Bertran: Diam. Relat. Mater., 13 (2004), 1494.

14) M. A. Ramírez R, P. C. Silva, E. J. Cora and V. J. Trava-Airoldi: Surf. Coat. Technol., 284 (2015), 235.

15) J. García-Céspedes, M. Rubio-Roy, M. C. Polo, E. Pascual, J. L. Andújar and E. Bertran: Diam. Relat. Mater., 16 (2007), 1131.

16) G. Capote, E. J. Corat and V. J. Trava-Airoldi: Surf. Coat. Technol., 260 (2014), 133.

17) N. Vidakis, A. Antoniadis and N. Bilalis: J. Mater. Process. Technol., 143-144 (2003), 481.

18) D. Panfil, P. Wach, M. Kulka and J. Michalski: Arch. Mech. Technol. Mater., 36 (2016), 18.

19) W. G. Cui, Q. B. Lai, L. Zhang and F. M. Wang: Surf. Coat. Technol., 205 (2010), 1995.

20) A. C. Ferrari and J. Robertson: Phys. Rev. B, 61 (2000), 14095.

21) N. Alba, C. Rincón, G. Zambrano, P. Prieto and H. Galindo: Superf. Vacio, 9 (1999), 267.

22) J. H. Wang, S. Zhang, H. L. Wang, K. E. Wong, Q. A. Zhou and Y. Z. Zhou: Thin Solid Films., 517 (2009), 5202. 